as the needle level has entered the vein blood will enter the chamber. Withdrawal of the needle at this stage will leave the cannula lying outside the vein with little chance of its being further manipulated into the lumen. This may be avoided by simply sliding the cannula over the needle after flashback (modified Seldinger technique).

Because local infection may be associated with a bacteraemia in up to $8^{\circ}$ of cases, culture of the cannula tip may provide the precise information needed for optimum therapy, particularly in immunodepressed patients or in those with damaged or prosthetic heart valves. As there is a strong correlation between skin flora and organisms recovered irom cannula tips, ${ }^{2}$ proper daily care of the fntravenous sites with the application of povidone iodine, which is both bactericida and fungicidal, will reduce the risk of cannularelated sepsis.

Dermot Phelan Myles MaCEvilly

Dr Steevens' Hospital,

Dublin 8

${ }_{1}$ Peter G, Lloyd-Still JD, Lovejoy FH, $\mathcal{f}$ Paediat 1972;80:78-82.

Banks DC, Yates DB, Cawdrey HM, et al. Lance 1970;i:443-5.

\section{Pain and arthritis in the African}

SIR,-In your leading article (23 February, $p$ 504) "Pain and arthritis in the African" there is no mention of yaws. In the old days before we had modern drugs and "different features" were "seen in different tribes," as you say "in rural areas . . . large distances from hospitals and often from doctors," many of these cases seemed to be recurrences of yaws after $30-40$ years or more and seemed to respond to the best we could offer in antiyaws treatment. It may be worthwhile to look at the serology, etc.

Cicely D Williams

Oxford

\section{Infections in the newborn}

SIR,-Discussing staphylococcal infections in the newborn Dr H B Valman (15 March, p 773) uses the word "pemphigus" for a rare bullous eruption which is rapidly fatal and very infectious if adequate antibiotics are not given. Pemphigus neonatorum is an inaccurate, misleading, and obsolete name which most authorities have long since dropped. Bullous impetigo is the correct terminology and fortunately large outbreaks are now rare.

Candida species are, of course, fungi and napkin area eruptions can both be caused or complicated by candidiasis. However, it should be noted that the photograph on $\mathrm{p} 774$ showing groin sparing is of irritant (frictional, chafing) napkin dermatitis, a type that is far less frequently complicated by candidiasis than is infantile seborrhoeic dermatitis.

\section{JULIAN VERBOV}

Royal Liverpool Children's Hospital, Liverpool L7 7DG

\section{The Jane Eyre syndrome}

SIR,-In your 1979 Christmas Quiz (22-29 December, p 1651) we were asked, "What is the Jane Eyre syndrome?" The answer was
"Patients who have relatives of whom they are ashamed-for example, those with dementia or incontinence.'

This is so much at variance with my interpretation of Jane Eyre's character that I have asked almost every member of the profession whom I have met this year if he or she has ever heard of this syndrome. So far I have had negative replies and I would be very grateful if anyone can tell me where it is described.

\section{H W Gallagher}

80 Belfast Rd,

Comber,

Newtownards, Co Down BT23 5QP

** Presumably "Jane Eyre syndrome" refers to $\mathrm{Mr}$ Rochester, who concealed the existence of his demented first wife Bertha, and not to Jane Eyre herself. The compiler of the quiz regrets that he cannot find the reference and we wonder whether any of our readers can help Mr Gallagher.-ED, BMF.

\section{Alive and well}

SIR,-Professor Geoffrey Rose and his colleagues in their paper "Heart disease prevention project" (15 March, p 747) have been kind enough to pay me what they evidently think is a posthumous tribute in their acknowledgments.

While thanking them, may I assure them that Tyrer is alive and well and living in South Wales?

Health and Safety Executive,

FRANK TYRER

Bristol BS1 6AN

\section{Higher medical training}

SIR,-I wonder if I may use your columns to bring one of two matters to the attention of those who either are in training in medicine and its allied specialties or wish to consider such a career, and of postgraduate deans and employing authorities.

The firsi item concerns the publication on 21 March of the Joint Committee on Higher Medical Training's Training Handbook and Third Report. This outlines the construction and working arrangements of the joint committee and the guidelines for training in medicine and paediatrics and their specialties as well as community and occupational medicine. The cost of the report is $f 1$, and copies may be obtained from the secretary of the JCHMT, Royal College of Physicians, 11 St Andrew's Place, London NW1 4LE.

The joint committee is aware that some posts approved either for the full period of five years or with qualified approval for shorter periods are now becoming due for reappraisal, so the new report does not contain a list of approved posts, as this would be misleading. We are at present considering the adoption of simplified methods of review, and revisitation where appropriate. At present it is not possible for the JCHMT to notify each individual hospital or authority when the time for review falls due, although in future it is hoped that this can be done. Postgraduate deans hold lists of currently approved posts, and I should be most grateful if they or the local employing authorities would draw the attention of the JCHMT (at the above address) to any posts where, owing to the lapse of time or change of circumstances in the post itself, reapproval is required. I particularly wish to stress that no approval will be withdrawn without a review, and that incumbents will in no way be penalised if approval of the post should lapse or be withdrawn during their tenure.

The visitation and approval scheme put into operation by the JCHMT since 1974 has involved an enormous amount of work and has established new standards of training for senior registrars. I am sure that all those concerned will be as anxious as I am that these standards be maintained by periodic reviews, and I ask for their co-operation in carrying this out. The help received from employing authorities and postgraduate deans in the preliminary reviews is gratefully acknowledged, and I am confident that I can rely on its continuation in the future.

Gavin B Shaw Chairman, Joint Committee
on Higher Medical Training Royal College of Physicians, London NW1 4LE

\section{Regional consultant contracts} and the organisation of specialties

SIR,-The Government's proposal in the consultative document Patients First that district health authorities should hold consultant contracts may at first sight seem logical, as other hospital medical staff will have their contracts with DHAs. But if consultants' contracts are removed from the regional health authorities there could be serious disturbances to the existing pattern of services as they affect the patient. This is because it is highly probable that districts would subsequently be threatened with the loss of part of their consultant cover, as local political pressures for improvement of this or that district specialty service began to make themselves felt. By placing consultant appointments on an essentially parochial basis I would envisage inevitable restrictions on clinical freedom.

There are several practical arguments against making such a sweeping change. Relatively few hospitals have a full team of consultants covering all specialties, with none of the consultants working at any other hospital. On the contrary, most hospitals share their consultants with at least one other hospital, which may be in another district or area. Most consultants attend two or more hospitals regularly, and in many cases consultants have duties in more than one district or sometimes in more than one area. Even those who do not may occasionally be requested to provide cover for annual leave or sick leave in another district or area.

The developments which have taken place since the inception of the NHS, including in particular the growth of specialties and subspecialties, require many of our hospital facilities to be more broadly organised than would be possible for a district health authority. The number of consultants in the United Kingdom is insufficient for each district health authority to be made independent of neighbouring districts in the provision of clinical services. This point applies with particular force in relation to specialties and subspecialties such as pathology, diagnostic radioisotope scanning, computed tomography, ultrasound, radiotherapy, cardiology, nephrology, and, indeed, all regional and supraregional services.

So far as can be forecast, district health 
authorities will always be interdependent in the planning and provision of clinical services. At regional level, however, the community's needs can be seen in perspective, catchment areas more fully comprehended, and local pressures more accurately assessed. With RHAs holding consultants' contracts services to patients are more fairly distributed; consultants can accept and treat patients from whatever source of referral; and the introduction of new techniques and the development and growth of new specialties is facilitated.

KenNeth Swinburne Wharfedale General Hospital,
Otley, W Yorks LS21 2LY

\section{Doctors and compulsory procedures}

SIR,-In their survey of the use of Section 47 of the National Assistance Act within the Northern Regional Health Authority during 1975-8 (8 March, p 739), Drs D P Forster and $\mathrm{P}$ Tiplady referred to the dearth of available information on how often this section is used as neither RHAs nor the DHSS now collect such information routinely.

Those who were medical officers of health to local authorities prior to the NHS and local government reorganisation will recollect that until 1973 we received each January a DHSS (or formerly Ministry) circular which advised on the content of the annual report we were statutorily bound to publish, and also requiring tabulated data on the work of the local authority health department in the previous year. This included a tabular return on the number of Section 47 orders obtained and the outcome of individual cases. The DHSS did not itself routinely publish collated national information on this section, but many medical officers of health summarised local action within their own annual reports; the latter were among the casualties of reorganisation. As responsibility for this section has remained since 1974 with the local authorities and their "proper officers" it is hardly surprising that no Health Service agency is now in a position to require an annual return on Section 47 cases.

The survey of Drs Forster and Tiplady is further evidence that the reasons for, and application of, this legislation is little known save to community physicians (Minerva's comment, 3 November, $p$ 1154, and my letter, 24 November, $p$ 1370). One must question the conclusion that Section 47 has been of little benefit simply on the grounds that a high proportion of patients died fairly soon after removal and few returned to their original residence. Few former medical officers of health or present "proper officers" consider Section 47 as other than a reserve power whose sole objective is to reduce the likelihood of an elderly or severely disabled individual dying in conditions of general neglect and squalor. Comparison with compulsory procedures under a Mental Health Act is not appropriate: in general these are to ensure an opportunity to diagnose and treat a person unable or unwilling by reason of his own illness to seek voluntary admission to a psychiatric unit.

Most experienced doctors concede that there is a small group of gravely ill patients who, though they are often living alone and in conditions of neglect, do not present criteria justifying compulsory action under the Mental Health Acts. Rather they per- versely reject the pleas of relatives, neighbours, and professional advisers to accept some form of institutional care if only to reduce terminal suffering and distress. It may be arguable whether the medical "proper officer" is the appropriate person authorised to seek compulsory removal in such cases, but it would be an uncaring society that did not devise some legislation to cover these situations.

G R BRACKENRIDGE Northallerton Health District, Northallerton, N Yorks DL6 1 JG

\section{Medically qualified preclinical academics}

SIR,-Could I comment on the letter by my friend $\mathrm{Dr}$ David Bowsher (16 February, p 485) ? All preclinical teachers are concerned about the continuing decline in the number of their medically qualified colleagues, but I wonder if the sole reason is the pay differential that Dr Bowsher would like to abolish. Undoubtedly it plays some part, but there is an additional factor, to which Dr R R Sturrock (2 February, p 335) alluded-that is, the increasing orientation of students away from science, whether preclinical or clinical. This is, of course, a manifestation of a major social trend, and is not susceptible to "local" solutions.

But the pay issue is important. Dr Bowsher states the case for comparability with epidemiologists, Medical Research Council (MRC) administrators, BMA staff, and the like. A comparison might equally be made with non-medical preclinical teachers, present now in appreciable numbers in most departments and in the majority of instances doing work which is precisely the same as their medically qualified colleagues. Surely this is the more valid comparison, based on the nature of the job and not on the possession of a particular basic qualification, obtained very often a long time ago. While some preclinical teachers do perform useful clinical work (and should be remunerated appropriately), the majority do not; and I can see no justification for a blanket raising of their remuneration to clinical levels. Perhaps the solution to $\mathrm{Dr}$ Bowsher's problem would be to reduce the remuneration of medical administrators to preclinical levels.

There is, however, a much greater difficulty in the recruitment of medically qualified preclinical staff, which has received little attention. When we advertise a vacant lectureship in this department the response is invariably (i) a large number of applications from science $\mathrm{PhDs}$, usually with a significant number of publications in reputable journals (often in fields very relevant to the practice of medicine) and, increasingly, with experience in teaching anatomy; and (ii) a small number of applications from medical graduates with only a basic qualification and no research or teaching experience. Even if more and better medical graduates came forward, it would be difficult to compare them with science postdoctoral candidates with the background in teaching and research we expect as a matter of course in candidates for university lectureships. In this context the basic medical qualification entitles the possessor merely to postgraduate training; it does not entitle him or her to step on to the academic ladder ahead of science graduates who have already the basic skills we require.
Tinkering with pay will solve few or no problems and create many more. We should instead explore other areas, in particular counteracting the antiscience bias among students and developing ways of encouraging both students and recent graduates to train in the basic medical sciences. Such action can be effective only if taken at the national level by the University Grants Committee and MRC, but it will require also changes in our own approach and teaching in the preclinical departments themselves. These are the areas in which the BMA should use its muscle.

E J ClegGG

University Department of Anatomy, Marischal College,
Aberdeen AB9 1AS

\section{A successful economy drive}

SIR,-In recent months, we have made strenuous and patriotic efforts to stem the profligacy which abounds in our health district. Our financial worries, it is true, must seem petty and parochial when set against those of our colleagues at Papworth hospital. But they are of a somewhat different order. The problem is not so much to find money for replacing time-expired coronary arteries but to find money for the unheroic, run-of-themill, routine-boring old hernias, piles, cataracts, and such-which characterise the bulk of our work. It is the type of work, one instinctively feels, which the originators of the National Health Service might have had in mind.

The clinical members of our district management team have just finished taking decisions which could lead to cuts in those basic if unglamorous aspects of hospital life"balancing the books," as it is called. The morality and mechanics of this exercise in accountancy, for those who have had to carry it out, are at least as debatable (although they hardly ever are debated) as are the arguments for and against the funding of heart and kidney transplants, with one crucial difference: any cuts will profoundly affect incomparably larger numbers of patients.

In considering cuts, should the clinicianmanager-a doctor-be seen by colleagues and patients to connive at the dismemberment of basic health care in his local community? Or should he, against the odds, and with no clear lead from his professional organisations, strive to put "patients first" ? And how can he set about doing just that without at once being accused of abrogating his responsibility to manage ? These really are important questions.

The rate of financial growth allowed to the NHS this coming financial year is one half of $1_{0}^{\circ}$-and this in a country notorious for spending a lesser proportion of its wealth on medicine than any other comparably civilised nation. According to the Secretary of State for Social Services, this rate of growth will prove insufficient "... to cope with an aging population, to keep up with medical advances, and to maintain standards." Quite.

Not to worry. Our economy drive has been successful. We have made savings amounting to over $£ 100000$ - a sum which, by felicitous irony, just matches the award from central funds to Papworth hospital.

Peter V Scott

Department of Anaesthetics, Bromsgrove, Worcs 